\title{
ERRATUM
}

\section{Microbial structuring of marine ecosystems}

\section{Farooq Azam and Francesca Malfatti}

Nature Reviews Microbiology 5, 782-791 (2007), doi: 10.1038/nrmicro1747

In the above article, an arrow was missing from figure 1 . The correct figure is shown below. In the same article, the legend to figure 4 should have indicated that the figure was first published in reference 145 . We wish to apologize to the author, and to readers, for any confusion caused.

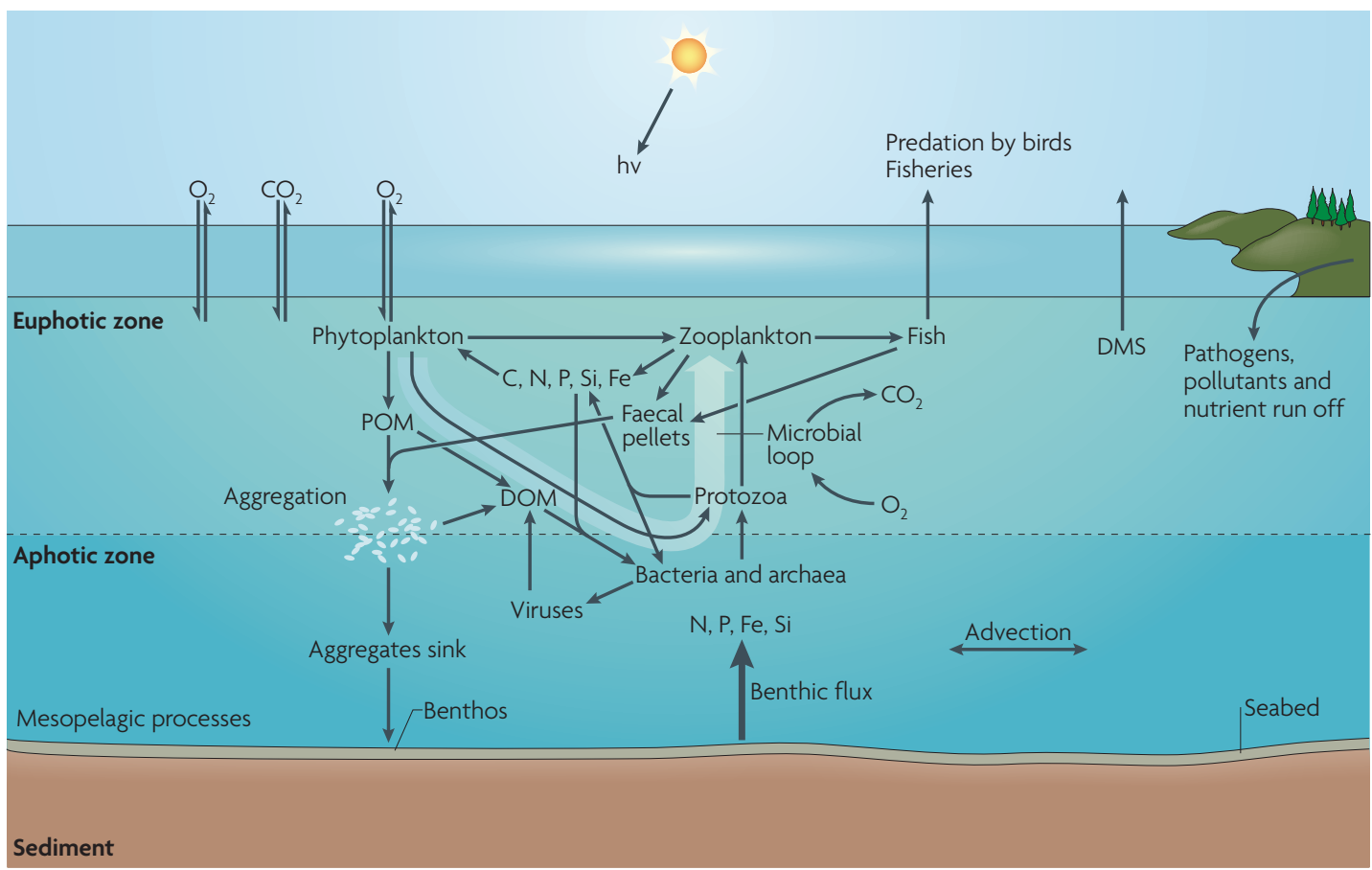

